\title{
Extended resection in pancreatic metastases: feasibility, frequency, and long-term outcome: a retrospective analysis
}

Georg Wiltberger ${ }^{1 *}$, Julian Nikolaus Bucher ${ }^{2}$, Felix Krenzien ${ }^{3}$, Christian Benzing ${ }^{3}$, Georgi Atanasov³, Moritz Schmelzle ${ }^{3}$, Hans-Michael Hau ${ }^{1+}$ and Michael Bartels ${ }^{1+}$

\begin{abstract}
Background: Metastases to the pancreas are rare, accounting for less then $2 \%$ of all pancreatic malignancies. However, both the benefit of extended tumor resection and the ideal oncological approach have not been established for such cases; therefore, we evaluated patients with metastasis to the pancreas who underwent pancreatic resection.

Methods: Between 1994 and 2012, 676 patients underwent pancreatic surgery in our institution. We retrospectively reviewed patients' medical records according to survival, and surgical and non-surgical complications. Student's t-test and the log-rank test were used for statistical analysis.

Results: Eighteen patients $(2.7 \%)$ received resection for pancreatic metastases (12 multivisceral resections and 6 standard resections). The pancreatic metastases originated from renal cell carcinoma $(n=10)$, malignant melanoma $(n=2)$, neuroendocrine tumor of the ileum $(n=1)$, sarcoma $(n=1)$, colon cancer $(n=1)$, gallbladder cancer $(n=1)$, gastrointestinal stromal tumor $(n=1)$, and non-small cell lung cancer $(n=1)$. The median time between primary malignancy resection to metastasectomy was 83 months (range, 0-228 months). Minor surgical complications (Grade I-IIla) occurred in six patients (33.3\%) whereas major surgical complications (Grade Illb-V) occurred in three patients (16.6\%). No patients died during hospitalization. The median follow-up was 76 months (range, 10-165 months). One-year, 3-year and 5-year survival for standard resection versus multivisceral resection was 83, 50, and $56 \%$ versus 83, 66, and 50, respectively. Twelve patients died after a median of 26 months (range, 5-55 months). Conclusions: A surgical approach with curative intent is justified in select patients suffering from metastases to the pancreas and offers good long-term survival. The resection of pancreatic metastases of different tumor types was associated with favorable morbidity and mortality when compared with resection of the primary pancreatic malignancies. Our findings also demonstrated that multivisceral resection was feasible, with acceptable long term outcomes, even though morbidity rates tended to be higher after multivisceral resection than after standard resection.
\end{abstract}

Keywords: Multivisceral resection, Metastases to the pancreas, Pancreaticoduodenectomy

\footnotetext{
* Correspondence: georg.wiltberger@medizin.uni-leipzig.de

${ }^{\dagger}$ Equal contributors

'Department of Visceral, Transplantation, Thoracic, and Vascular Surgery,

University Hospital Leipzig, 04103 Leipzig, Germany

Full list of author information is available at the end of the article
} 


\section{Background}

Metastases to the pancreas are rare and account only for 1-2 \% of all pancreatic malignancies [1]. Most primaries that spread to the pancreas are renal cell carcinomas (RCC), lung cancers, malignant melanomas, and malignancies of the gastrointestinal tract [2, 3]. However, at the time of diagnosis, patients often present with widespread systemic disease and therefore, no curative treatment is applicable. Several studies have demonstrated survival benefit and improved quality of life after complete metastasectomy for isolated lung or liver metastases [4, 5]. Therefore, extended surgical intervention is a well-established approach in a multidisciplinary concept for select patients suffering from colorectal or pulmonary metastases in the liver [6]. However, extended surgery for pancreatic metastasectomy is rare and remains debatable as there have been few studies on the procedure, all of which have reported controversial results [7-9]. Patients with localized extrapancreatic disease appear to be suitable for pancreatic resection but the ideal oncological approach has not been established and the benefit of multivisceral resection (MVR) remains undetermined. Our aim was to assess the frequency and feasibility of MVR for metastases to the pancreas. We also analyzed the influence of MVR on perioperative and long-term outcomes compared with standard resection.

\section{Methods}

We retrospectively analyzed the medical records of patients who underwent pancreatic resection at the Department of Visceral, Transplant, Thoracic, and Vascular Surgery, University Hospital Leipzig, Leipzig, Germany, between 1994 and 2012.

For this study ethical approval was obtained from the institutional local ethical committee (AZ 318-1406102014, Ethical committee of the University Clinic Leipzig, Leipzig). Due to the retrospective design of the study and accordingly national guidelines, the local ethic committee confirmed, that informed consent was not necessary from participants.

All patients were operated on with curative intent. We included patients with extrapancreatic spread in this study only when extrapancreatic disease appeared to be resectable, and we excluded patients with primary tumors that had infiltrated the pancreas through direct extension.

We assessed the following patient characteristics: sex, age, body mass index, preoperative symptoms, comorbidities, type of resection, duration of operation, required units of fresh frozen plasma and/or packed red blood cells, median length of stay on the intensive care unit, total length of stay, time between surgery for the primary tumor and pancreatic resection, postoperative morbidity according to Clavien-Dindo classification [10], presence of pancreatic fistulae according to the International Study Group for Pancreatic Fistula criteria [11], hospital mortality defined as death within the first 60 days after resection, overall survival rate, disease-free survival, and histopathological data. Patients who died within the first 90 days after resection were excluded from further statistical analysis. MVR was defined as resection of one additional organ, excluding the spleen.

\section{Statistics}

Data are presented as median (range) unless otherwise specified. Statistical differences between groups were determined by Student's $t$-test. Student's $t$-test and the log-rank test were used to analyze continuous variables and overall survival excluding in-hospital mortality, respectively. All statistical analyses were performed with SPSS for Windows (version 12.0, SPSS Inc., Chicago, IL, USA).

\section{Results}

Patient characteristics and preoperative symptoms

Between 1994 and 2012, 676 patients were scheduled for pancreatic surgery, of which $18(2.6 \%)$ received resection for metastatic disease of the pancreas (Table 1). Eight of the patients were men and 10 were woman with a median age of 65 years (range, 22-75 years) and a median body mass index of $25.4 \mathrm{~kg} / \mathrm{m}^{2}$ (range, $\left.18-31 \mathrm{~kg} / \mathrm{m}^{2}\right)$. Four patients $(22.2 \%)$, had diabetes mellitus type II and $13(72.2 \%)$ patients received medication for high blood pressure (Table 2). At the time of diagnosis of pancreatic metastases, eight patients (44.4\%) had one or more tumor-related symptoms including weight loss $(n=8)$, abdominal pain $(n=8)$, decrease in general performance $(n=5)$, obstructive jaundice $(n=2)$, or absence of appetite $(n=1)$. Ten patients $(55.5 \%)$ had no specific symptoms and the diagnosis of pancreatic metastases was obtained through routine follow-up examinations.

\section{Primary tumor characteristics}

The majority of pancreatic metastases originated from renal cell carcinoma ( $n=10 ; 55.5 \%)$, malignant melanoma $(n=2)$, and neuroendocrine tumor of the ileum $(n=1)$. Other primaries included sarcoma $(n=1)$, colon cancer $(n=1)$, gallbladder cancer $(n=1)$, gastrointestinal stromal tumor $(n=1)$, and non-small cell lung cancer $(n=1)$. Metastases to the pancreas were located mainly in the pancreatic head $(n=10)$ followed by the total pancreas $(n=3)$ and the cauda region $(n=3)$. In two patients, metastases were simultaneously located in the corpus and cauda region. Eleven patients $(61 \%)$ had simultaneous metastases in other organs and seven of these patients underwent 
Table 1 Patient characteristics

\begin{tabular}{|c|c|c|c|c|c|c|}
\hline Case No. & Primary Malignancy & $\begin{array}{l}\text { Location in the pancreas } \\
\text { (sync./metac.) }\end{array}$ & $\begin{array}{l}\text { Time interval } \\
\text { (months)* }^{*}\end{array}$ & Type of Operation & $\begin{array}{l}\text { further metastases at detection } \\
\text { of pancreatic metastasis }\end{array}$ & $\begin{array}{l}\text { tumor recurrence/ } \\
\text { survival status }^{\dagger}\end{array}$ \\
\hline 1 & RCC & Head (sync.) & 0 & PPPD + Nephrectomy & no & no/alive \\
\hline 2 & Lung-Cancer & Cauda (metac.) & 83 & DP + Gastrectomy + Splenectomy + vertebral body resection & Vertebral body (s) & no/TRD \\
\hline 3 & $\mathrm{RCC}$ & Head (metac.) & 142 & PPPD & no & no/Non-TRD \\
\hline 4 & $\mathrm{RCC}$ & Head (sync.) & 0.8 & PPPD & no & Local recurrence/alive \\
\hline 5 & $\mathrm{RCC}$ & Head/Corpus/Cauda (metac.) & 120 & Enucleation in pancreatic head + DP + Splenectomy & Lung (s) & Thyroid/TRD \\
\hline 6 & $\mathrm{RCC}$ & Head/Corpus/Cauda (metac.) & 132 & TP + Spleenectomy + distal Gastrectomy & Thyroid (s) & no/TRD \\
\hline 7 & Gallblader-Cancer & Head (sync.) & 0 & PPPD + Liver resection (SII SIII) & Liver (a) & yes/TRD \\
\hline 8 & $\mathrm{RCC}$ & Corpus/Cauda (sync.) & 17 & $\mathrm{DP}+$ Spleen + Colon + Jejunom & Pulmo (s) & no/TRD \\
\hline 9 & GIST & Head (metac.) & 34 & PPPD + Hemicolectomy & Liver (a) & yes/alive \\
\hline 10 & $\mathrm{RCC}$ & Head (metac.) & 106 & Whipple & no & Lung/TRD \\
\hline 11 & Sarcoma & Head (sync.) & 0 & Whipple + Hemihepatectomy + Hemicolectomy & Liver (s) & Liver/TRD \\
\hline 12 & $\mathrm{RCC}$ & Head/Corpus/Cauda (metac.) & 66 & TP + Spleen & no & Cerebral/TRD \\
\hline 13 & Melanoma & Head/Corpus/Cauda (metac.) & 90 & TP + Segemental liver resection & Liver (a) & Liver/alive \\
\hline 14 & $\mathrm{RCC}$ & Cauda (metac.) & 123 & DP & Pulmo (s) & Thyroid/TRD \\
\hline 15 & Melanoma & Head (metac.) & 228 & PPPD + Hemihepatectomy & Liver (a) & Liver/TRD \\
\hline 16 & $\mathrm{RCC}$ & Head (sync.) & 0 & $\mathrm{DP}+$ Spleen + Nephrctomy & no & no/alive \\
\hline 17 & Colon-Cancer & Head (metac.) & 29 & PPPD + Liver resection (Lobus caudatus) & Liver (s) & no/alive \\
\hline 18 & NET lleum & Head (sync.) & 78 & PPPD + Jejunum & Jejunum (s) & no/alive \\
\hline
\end{tabular}

sync. indicates synchronous metastases to the pancreas; metac. indicates metachronous metastases to the pancreas; ${ }^{*}$ interval from resection of primary tumor to resection of pancreatic metastasis; $\square$ excluding

pancreas (a, after; s, synchronous; $p$, prior); $\uparrow$ at time of study; RCC indicates renal cell carcinoma; NET indicates neuroendocrine tumor; PPPD indicates pylorus-preserving pancreaticoduodenectomy; DP indicates distal pancreatectomy; TP indicates total pancreatectomy; TRD indicates tumor-related death 
Table 2 Demographic data

\begin{tabular}{|c|c|c|c|c|}
\hline Characteristics & Total $(n=18)$ & Standard Resection $(n=6)$ & Multivisceral resection (MVR; $n=12)$ & $p$-value $e^{*}$ \\
\hline Age (median; Range) & $65(22-75)$ & $70(49-75)$ & $58(22-72)$ & 0.074 \\
\hline \multicolumn{5}{|l|}{ Gender (\%) } \\
\hline Female & $10(55.6)$ & $4(22.2)$ & $6(33.3)$ & 0.548 \\
\hline Male & $8(44.4)$ & $2(11.1)$ & $6(33.3)$ & 0.548 \\
\hline BMI (median; Range) & $25.4(18-31.1)$ & $26(21.7-30.4)$ & $24.4(18-31.1)$ & 0.264 \\
\hline \multicolumn{5}{|l|}{ Comorbidities (\%) } \\
\hline Diabetes mellitus & $4(22.2)$ & $2(11.1)$ & $2(11.1)$ & 0.932 \\
\hline Arterial hypertension & $13(72.2)$ & $5(33.3)$ & $8(44.4)$ & 0.817 \\
\hline Metabolic syndrome & $3(16.7)$ & $1(5.6)$ & $2(11.1)$ & 0.932 \\
\hline COPD* & $2(11.1)$ & $0(0)$ & $2(11.1)$ & 0.104 \\
\hline CAD & $5(27.8)$ & $1(5.6)$ & $4(22.2)$ & 0.374 \\
\hline \multicolumn{5}{|l|}{ Preoperative symptoms (\%) } \\
\hline Asymptomatic & $10(55.6)$ & $4(22.2)$ & $6(33.3)$ & 0.548 \\
\hline \multicolumn{5}{|l|}{ Symptomatic } \\
\hline Weight loss & $8(44.4)$ & $3(16.7)$ & $5(33.3)$ & 0.984 \\
\hline Abdominal pain & $7(38.9)$ & $3(16.7)$ & $4(33.3)$ & 0.682 \\
\hline obstructive jaundice & $2(11.1)$ & $0(0)$ & $2(11.1)$ & 0.103 \\
\hline decrease in general performance & $3(16.7)$ & $1(5.6)$ & $2(11.1)$ & 0.742 \\
\hline absence of appetite & $1(5.6)$ & $1(5.6)$ & $0(0)$ & 0.170 \\
\hline Sleep hyperhidrosis & $1(5.6)$ & $0(0)$ & $1(5.6)$ & 0.166 \\
\hline New onset of diabetes & $1(5.6)$ & $0(0)$ & $1(5.6)$ & 0.166 \\
\hline
\end{tabular}

COPD indicates chronic obstructive pulmonary disease; CAD indicates coronary artery disease

simultaneous resection of the extrapancreatic masses. The other four patients received a subsequent procedure (metastasectomy of the lungs in three cases and one thyroidectomy). In four patients, the diagnosis of pancreatic metastases coincided with that of the primary malignancy, which was RCC in all cases. In three of these patients, primary tumor and metastatic resection was performed as one procedure. In one patient, an intraoperative biopsy of the pancreatic head during tumor-nephrectomy confirmed metastatic disease and metastasectomy was performed four weeks later. In three patients (30\%) with RCC multifocal lesions in the resected specimens were detected.

\section{Surgical procedures}

The median time between resection of the primary malignancies to resection of the pancreatic metastases was 83 months (range, 0-228 months). The most frequently used surgical procedures were Whipple-procedure/pylorus-preserving pancreaticoduodenectomy (PPPD) in 10 patients and distal pancreatectomy (DP) in five patients. In four patients, DP was performed with and, in one patient, without splenectomy. In three patients, total pancreatectomy was performed, with simultaneous splenectomy in two cases. MVR was performed in 12
(66.6 \%) patients. Five patients who received Whippleprocedure/PPPD or total pancreatectomy also required additional liver resection to remove synchronous extrapancreatic metastases. Two of these patients underwent additional bowel resection and three patients received additional gastric or bowel resection. In two patients who underwent PPPD or DP, simultaneous nephrectomy was performed and one patient received simultaneous vertebral body resection for solitary bone metastasis. The median operation time for all procedures was 322 min (range, 193-591 $\mathrm{min}$ ). Ten patients received intraoperative fresh frozen plasma (median 3, range 0-18 units) and/or packed red blood cells (median 2, range, 0-10 units). Microscopically-free resection margins (R0) were achieved in $77.7 \%$ of the patients.

\section{Perioperative outcome}

Length of stay in the intensive care unit and total length of stay were 2 days (range, 1-50 days) and 21.5 days (range, 12-55 days), respectively (Table 3). No patients died during hospitalization. Postoperative complications occurred in 11 patients (61.1\%), of which $81 \%$ were surgical and $18 \%$ were non-surgical complications. Minor surgical complications (Grade I-IIIa, $n=6$ ) were: new onset of diabetes in two patients; wound infection 
Table 3 Perioperative data

\begin{tabular}{|c|c|c|c|c|}
\hline Data & Total $(n=18)$ & StandardResection $(n=6)$ & Multivisceral resection $(n=12)$ & $p$-Value \\
\hline \multicolumn{5}{|l|}{ Operative Data } \\
\hline Length of operation (min) & $322(193-591)$ & $261(193-462)$ & $346(216-591)$ & 0.137 \\
\hline FFPs and/or pRBCs & $3(0-18) 2(0-10)$ & $3(0-3) 1(0-8)$ & $3(0-18) 4(1-10)$ & $0.291 / 0.838$ \\
\hline \multicolumn{5}{|l|}{ Perioperative Data } \\
\hline LOS-ICU & $2(1-50)$ & $1(1-3)$ & $3(1-50)$ & 0.205 \\
\hline T-LOS & $21(12-55)$ & $20(16-2)$ & $23(12-55)$ & 0.898 \\
\hline Time interval* & $72(0-228)$ & $113(0-142)$ & $31.5(0-228)$ & 0.259 \\
\hline Follow-up & $76(10-165)$ & $59(28-95)$ & $53(10-165)$ & 0.104 \\
\hline 1-year/3-year/5-year survival & $84 / 66 / 55$ & $83 / 50 / 56$ & $83 / 66 / 50$ & \\
\hline \multicolumn{5}{|l|}{ Histopathological data } \\
\hline $\mathrm{RO} / \mathrm{R} 1 / \mathrm{R} 2$ & 15/3/0 (83.3/16.7/0) & $7 / 0 / 0(38.9 / 0 / 0)$ & 8/3/0 (44.4/16.7/0) & 0.081 \\
\hline Negative/positive LN & $13 / 5(72.2 / 27.8)$ & 6/1 (33.3/5.6) & $7 / 4(38.9 / 22.2)$ & 0.278 \\
\hline \multicolumn{5}{|c|}{ Postoperative Complications (Clavien-Dindo classification) } \\
\hline \multicolumn{5}{|l|}{ Non-Surgical related complications } \\
\hline Minor (Grade I-IIla) & $0(0)$ & $0(0)$ & $0(0)$ & 0 \\
\hline Major (Grade IIIb - IV) & $2(11.1)$ & $1(5.6)$ & $1(5.6)$ & 0.681 \\
\hline \multicolumn{5}{|l|}{ Surgical related complications } \\
\hline Minor (Grade I-IIla) & $6(33.3)$ & $2(11.1)$ & $4(22.2)$ & 0.781 \\
\hline Major (Grade IIIb - IV) & $3(16.7)$ & $1(5.6)$ & $2(11.1)$ & 0.932 \\
\hline \multicolumn{5}{|l|}{ Overall Morbidity } \\
\hline Mortality (60 days) & $0(0)$ & $0(0)$ & $0(0)$ & 0 \\
\hline \multicolumn{5}{|l|}{ Overall-Mortality } \\
\hline \multicolumn{5}{|l|}{ Follow up } \\
\hline Local recurrence & $1(5.6)$ & $1(5.6)$ & $0(0)$ & 0.166 \\
\hline Extrapancreatic Recurrence & $9(50)$ & $4(22.2$ & $5(33.3)$ & 0.565 \\
\hline Further surgical interventions & $6(33.3)$ & $2(11.1)$ & $4(22.2)$ & 0.781 \\
\hline
\end{tabular}

FFP, fresh frozen plasma; pRBC, packed red blood cells; LOS-ICU, length of stay in intensive care unit; T-LOS; total length of stay

$(n=2)$, which was managed conservatively; and pancreatic fistula grade $\mathrm{B}$ with prolonged use of abdominal drainage $(n=2)$. Major surgical complications (Grade IIIb-V, $n=3$ ) were: leakage from the hepaticojejunostomy site with the need for relaparotomy, bowel perforation with the need for relaparotomy, biliary leakage after combined liver and pancreas resection that had to be treated with an interventional drain, and a wound infection that required re-operation under general anesthesia, with each complication occurring in one case. Major non-surgical complications (Grade IIIb-V, $n=2$ ) occurred in two patients and both developed pneumonia requiring readmission to the intensive care unit.

\section{Follow-up and survival}

No patient was lost to follow-up and the median followup time was 76 months (range, 10-165 months) with 12 patients dying after a median of 26 months (range, 5-55 months). Death was tumor-related in 11 cases and non- tumor-related in one case. During follow-up, nine patients suffered from extrapancreatic recurrence. Five patients received further surgical treatment including thyroidectomy, liver resection, or metastasectomy of the lungs. In one patient, cerebral metastasis was treated by stereotactic irradiation. Local recurrence of pancreatic disease was seen in one patient and was successfully controlled by total resection of the pancreatic remnant.

In our sample, the time interval between resection of the primary malignancy and detection of metastatic disease did not correlate significantly with overall survival after resection of the pancreatic metastases. KaplanMeier curve for survival with standard resection versus MVR are shown in Fig. 1. One-, 3- and 5-year survival for standard resection versus MVR was 83,50 , and $56 \%$, versus 83,66 , and $50 \%$, respectively.

\section{Discussion}

Surgical interventions for metastatic disease have increased over the last decade, concurrent with considerable 


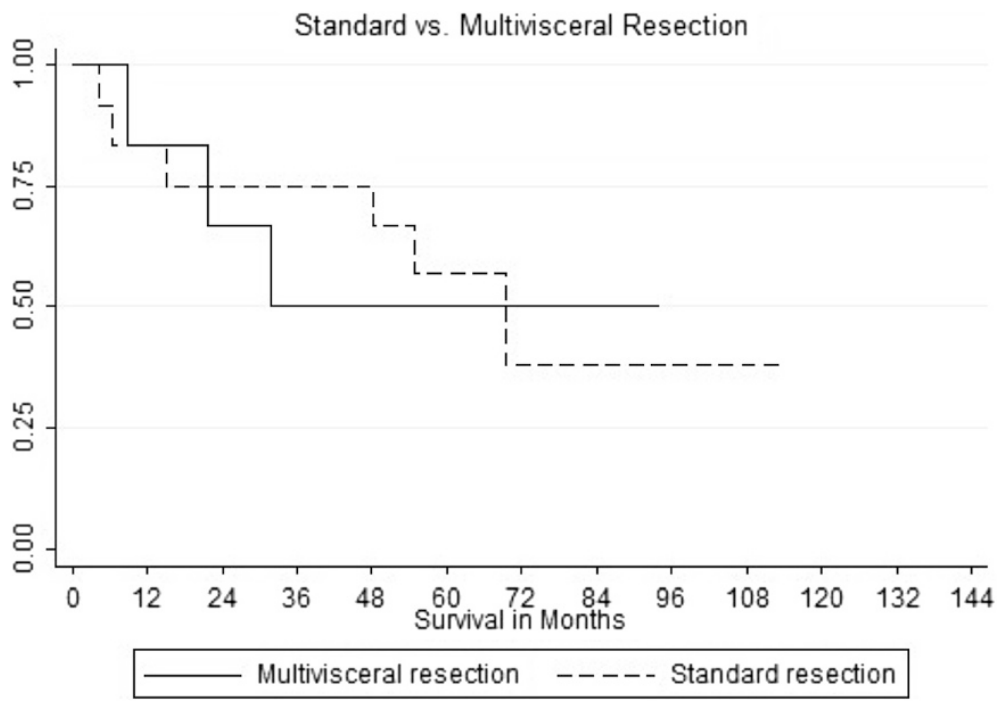

Fig. 1 Kaplan-Meier survival curve showing survival for patients who underwent standard resection (solid line) versus multivisceral resection (dotted line) (in months)

improvement in quality of life and long-term survival of up to 10 years following resection for the most common (liver or lung) metastases $[12,13]$. As a result, surgical resection of metastases is now an integral part of a multidisciplinary oncological approach [6]. In contrast, metastases to the pancreas are uncommon and the majority of patients present with no specific symptoms [14] and with non-resectable widespread disease at the time of diagnosis. However, in cases of isolated disease, surgical intervention may be beneficial in terms of overall survival, even in patients with localized extrapancreatic metastases, and in terms of the need for MVR to obtain complete tumor-free resection margins.

Based on our experience, surgical intervention is justified in select patients diagnosed with metastases to the pancreas. Our data showed that surgical resection for pancreatic metastases is feasible and provides good long term results, even in patients undergoing MVR. Perioperative morbidity and in-hospital mortality were comparable to studies evaluating standard pancreatic resection for primary malignancies [15]. In our study, morbidity after MVR tended to be higher than after standard resection. However, MVR for pancreatic metastases should not be considered an absolute contraindication for surgery, because our results indicated equivalent overall survival in the MVR group.

The limitations of our study are the small cohort and the absence of a control group treated by other therapeutic strategies. Therefore, general recommendations cannot be made based on our data, even though complete resection (R0) is generally considered a good prognostic marker for patients' overall survival [16]. For instance, long-term survival of 10 years can be seen after complete resection of colorectal liver metastases, which emphasizes the importance of this therapeutic option [12]. In our study, the rate of microscopically-free resection margins $(77.7 \%)$ did not differ from other studies reporting positive resection margins for pancreatic cancer of $17-30 \%$ [17-19].

Because of the high incidence of metastatic disease originating from RCC, the most valid conclusions can be provided for this tumor type. Consequently, most reported data refer to RCC and are comparable with our results in terms of incidence and overall survival $[1,8,20]$. In our study, 10 patients (55.5\%) had pancreatic metastases from RCC and the overall survival of this subgroup was $60 \%$. In a recently published review, Tanis et al. reported a 5-year survival rate of $72.6 \%$ in 311 cases following pancreatic surgery for RCC metastases [21]. In this context, time of metastatic onset is discussed as a prognostic marker for long-term survival. A small number of studies have observed a trend to better overall survival in patients with long disease-free interval when evaluating primary tumor resection and onset of metastases to the pancreas. We did not see a similar effect in our patients because overall survival did not differ significantly between patients with longer disease-free interval. These findings are supported by the results of a meta-analysis which identified 15 studies addressing pancreatic metastasectomy for RCC [1]. In the univariate analysis, time from resection of the primary tumor did not affect overall survival.

Many changes have been made, regarding the oncological treatment for metastatic RCC. Individualized immunotherapy based on immunoreactive cytokines and/ or antiangiogenetic agents (e.g. bevacizumab, sunitinib, 
and sorafenib) have showed encouraging results. Therefore, surgical resection should not be considered as the only therapeutic option: An interdisciplinary approach including visceral surgeons, urologists and oncologists should be performed for the treatment against pancreatic metastases to obtain sufficient synergistic antitumor effects. However, the best way to combine surgery with oncological treatment has to be evaluated addressed by future studies.

Pancreatic metastases can occur after a long diseasefree interval, with a median time between resection of the primary tumor and detection of pancreatic metastases of 72 months (range, 0-228 months). This biological tumor behavior reflects the importance of a prudent long-term follow-up in these patients, even if specific symptoms are missing. This point is supported by our findings, which revealed that only $44.4 \%$ of the patients had specific symptoms. We recommend that regular follow-up including radiological imaging should be performed even after a long disease-free interval.

Very few data are available regarding the potential impact of MVR for pancreatic metastases on morbidity and mortality because of the low proportion of patients with MVR in most of the published studies [20]. However, in our study, the majority of patients $(66.6 \%)$ were treated by a multivisceral approach. In a retrospective analysis, Strobel et al. compared patients who received either standard resection or MVR for pancreatic metastases of different tumor types [22]. The authors reported no significant difference for morbidity and mortality between groups, although morbidity in the MVR group tended to be higher. Also, the majority of complications were surgical, with one patient dying in each group. These results are comparable to our results where the majority of postoperative complications were also surgical. We also saw that major surgical complications occurred more frequently in the MVR group, although this result was not statistically significant. Because of its potentially beneficial impact on long-term survival, we do not consider that MVR is an absolute contraindication but that the increased operative risk should be considered in the decision making process. The overall morbidity in our study was not increased compared with the reported morbidity rate for resection of primary pancreatic malignancies of up to $58.5 \%$, even though major surgical complications occurred more frequently in our study [15]. This might be attributable to the high proportion of patients who underwent MVR.

During our study follow-up, only one patient suffered from tumor recurrence in the pancreas and this was successfully treated by resection of the pancreatic remnant without further tumor recurrence. This might be interpreted as a sign of good local tumor control and is supported by other studies [22].
In total, nine of our patients (50\%) developed extrapancreatic recurrence, of which five (33.3 \%) had undergone previous MVR. Four patients received primarily combined liver and pancreas resection for metastases of sarcoma or gallbladder cancer ( $n=1$ for each cancer) and for metastases of malignant melanoma in two cases. In the latter patients, hepatic recurrence occurred and further surgical intervention was performed in one patient, who is still alive. These results are consistent with other reports showing a survival rate of $50 \%$ after liver resection for malignant melanoma [23]. Therefore, the type of the primary tumor should also be considered when deciding on surgery and the patient should be informed of the risk of recurrence.

\section{Conclusions}

A surgical approach with curative intent is justified in select patients suffering from metastases to the pancreas and offers good long-term survival. Our results showed that resection of pancreatic metastases of different tumor types was associated with favorable morbidity and mortality when compared with resection of the primary pancreatic malignancies. Our findings also demonstrated that MVR was feasible, with acceptable long term outcomes, even though morbidity tended to be higher than with standard resection.

\section{Abbreviations \\ DP: distal pancreatectomy; MVR: multivisceral resection; PPPD: pylorus-preserving pancreaticoduodenectomy; RCC: renal cell carcinoma.}

\section{Competing interests}

The authors declare that they have no competing interests.

\section{Authors' contributions}

$\mathrm{GW}, \mathrm{JB}, \mathrm{HMH}$ and $\mathrm{MB}$ were responsible for the study conception and design: GW, CB, JB, FK, GA, and $H M H$ were responsible for data acquisition; GW, JB, $\mathrm{HMH}$, and $\mathrm{MB}$ analyzed and interpreted the data; $\mathrm{GW}, \mathrm{JB}$, and $\mathrm{HMH}$ drafted the manuscript; and $\mathrm{FK}, \mathrm{JB}, \mathrm{CB}, \mathrm{MS}, \mathrm{HMH}$ and $\mathrm{MB}$ critically revised the manuscript. All authors read and approved the final manuscript.

\section{Acknowledgements}

The authors declare that no funding was received for the study.

\section{Author details}

'Department of Visceral, Transplantation, Thoracic, and Vascular Surgery, University Hospital Leipzig, 04103 Leipzig, Germany. ${ }^{2}$ Department of Surgery, University Hospital Großhadern (LMU), Munich, Germany. ${ }^{3}$ Department of General, Visceral, and Transplant Surgery, Charité - Universitätsmedizin Berlin, Campus Virchow Klinikum, Augustenburger Platz 1, 13353 Berlin, Germany.

Received: 6 May 2015 Accepted: 7 December 2015

Published online: 11 December 2015

\section{References}

1. Reddy S, Wolfgang CL. The role of surgery in the management of isolated metastases to the pancreas. Lancet Oncol. 2009;10:287-93.

2. Eidt $S$, Jergas $M$, Schmidt $R$, Siedek M. Metastasis to the pancreas-an indication for pancreatic resection? Langenbecks Arch Surg. 2007;392: 539-42.

3. Sellner F, Tykalsky N, De Santis M, Pont J, Klimpfinger M. Solitary and multiple isolated metastases of clear cell renal carcinoma to the pancreas: an indication for pancreatic surgery. Ann Surg Oncol. 2006;13(1):75-85. 
4. Quiros RM, Scott WJ. Surgical treatment of metastatic disease to the lung. Semin Oncol. 2008;35(2):134-46.

5. Choti MA, Sitzmann JV, Tiburi MF, Sumetchotimetha W, Rangsin R, Schulick $\mathrm{RD}$, et al. Trends in long-term survival following liver resection for hepatic colorectal metastases. Ann Surg. 2002;235(6):759-66.

6. Garden OJ, Rees M, Poston GJ, Mirza D, Saunders M, Ledermann J, et al. Guidelines for resection of colorectal cancer liver metastases. Gut. 2006;55 Suppl 3:iii $1-8$.

7. Hiotis SP, Klimstra DS, Conlon KC, Brennan MF. Results after pancreatic resection for metastatic lesions. Ann Surg Oncol. 2002;9(7):675-9.

8. Zerbi A, Ortolano E, Balzano G, Borri A, Beneduce AA, Di Carlo V. Pancreatic metastasis from renal cell carcinoma: which patients benefit from surgical resection? Ann Surg Oncol. 2008;15(4):1161-8.

9. Bahra M, Jacob D, Langrehr JM, Glanemann M, Schumacher G, Lopez-

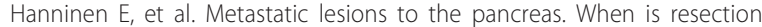
reasonable? Chirurg. 2008;79(3):241-8.

10. DeOliveira ML, Winter JM, Schafer M, Cunningham SC, Cameron JL, Yeo CJ, et al. Assessment of complications after pancreatic surgery: A novel grading system applied to 633 patients undergoing pancreaticoduodenectomy. Ann Surg. 2006;244(6):931-7. discussion 937-939.

11. Bassi C, Dervenis C, Butturini G, Fingerhut A, Yeo C, lzbicki J, et al. Postoperative pancreatic fistula: an international study group (ISGPF) definition. Surgery. 2005;138(1):8-13.

12. Tomlinson JS, Jarnagin WR, DeMatteo RP, Fong Y, Kornprat P, Gonen M, et al. Actual 10-year survival after resection of colorectal liver metastases defines cure. J Clin Oncol. 2007:25(29):4575-80.

13. Marudanayagam R, Ramkumar K, Shanmugam V, Langman G, Rajesh P, Coldham C, et al. Long-term outcome after sequential resections of liver and lung metastases from colorectal carcinoma. HPB (Oxford). 2009;11(8): 671-6.

14. Konstantinidis IT, Dursun A, Zheng H, Wargo JA, Thayer SP, Fernandez-del Castillo C, et al. Metastatic tumors in the pancreas in the modern era. J Am Coll Surg. 2010;211(6):749-53.

15. Addeo P, Delpero JR, Paye F, Oussoultzoglou E, Fuchshuber PR, Sauvanet A, et al. Pancreatic fistula after a pancreaticoduodenectomy for ductal adenocarcinoma and its association with morbidity: a multicentre study of the French Surgical Association. HPB (Oxford). 2014;16(1):46-55.

16. Rau BM, Moritz K, Schuschan S, Alsfasser G, Prall F, Klar E. R1 resection in pancreatic cancer has significant impact on long-term outcome in standardized pathology modified for routine use. Surgery. 2012;152(3 Suppl 1):S103-11.

17. Sohn TA, Yeo CJ, Cameron JL, Koniaris L, Kaushal S, Abrams RA, et al. Resected adenocarcinoma of the pancreas-616 patients: results, outcomes, and prognostic indicators. J Gastrointest Surg. 2000;4(6):567-79.

18. Howard TJ, Krug JE, Yu J, Zyromski NJ, Schmidt CM, Jacobson LE, et al. A margin-negative RO resection accomplished with minimal postoperative complications is the surgeon's contribution to long-term survival in pancreatic cancer. J Gastrointest Surg. 2006;10(10):1338-45. discussion 1345-1336.

19. Butturini G, Stocken DD, Wente MN, Jeekel H, Klinkenbijl JH, Bakkevold KE, et al. Influence of resection margins and treatment on survival in patients with pancreatic cancer: meta-analysis of randomized controlled trials. Arch Surg. 2008;143(1):75-83. discussion 83.

20. Niess H, Conrad C, Kleespies A, Haas F, Bao Q, Jauch KW, et al. Surgery for metastasis to the pancreas: is it safe and effective? I Surg Oncol. 2013; 107(8):859-64

21. Tanis PJ, van der Gaag NA, Busch OR, van Gulik TM, Gouma DJ. Systematic review of pancreatic surgery for metastatic renal cell carcinoma. Br J Surg. 2009:96(6):579-92

22. Strobel O, Hackert T, Hartwig W, Bergmann F, Hinz U, Wente MN, et al. Survival data justifies resection for pancreatic metastases. Ann Surg Oncol. 2009;16(12):3340-9.

23. Ryu SW, Saw R, Scolyer RA, Crawford M, Thompson JF, Sandroussi C. Liver resection for metastatic melanoma: equivalent survival for cutaneous and ocular primaries. J Surg Oncol. 2013;108(2):129-35.

\section{Submit your next manuscript to BioMed Central and we will help you at every step:}

- We accept pre-submission inquiries

- Our selector tool helps you to find the most relevant journal

- We provide round the clock customer support

- Convenient online submission

- Thorough peer review

- Inclusion in PubMed and all major indexing services

- Maximum visibility for your research

Submit your manuscript at www.biomedcentral.com/submit

) Biomed Central 